\title{
The antimicrobial peptide LL37 and its truncated derivatives potentiates proinflammatory cytokine induction by lipoteichoic acid in whole blood
}

\author{
ANNA GUSTAFSSON ${ }^{1}$, STEFANIE SIGEL ${ }^{2}$ \& LENNART LJUNGGREN $^{1}$ \\ ${ }^{1}$ Department of Biomedical Laboratory Science, Malmö University, Malmö, Sweden, and ${ }^{2}$ Biochemical Pharmacology, \\ University of Konstanz, Konstanz, Germany
}

\begin{abstract}
Interactions of bacterial and host products in activating the innate immune system is an important area to address. The role of lipoteichoic acid (LTA) in these interactions is particularly important because it is understudied in comparison to other factors. This study evaluated the effect of cationic peptides (CPs) on LTA-induced proinflammatory cytokine production in human whole blood and on purified leukocytes. Four different CPs of truncated derivatives from the known peptides LL37, BPI, and CP207 were used. Two of the CPs (IG33 and LL33), derivatives from LL37, potentiated S. aureus LTA induced TNF $\alpha$, IL-6 and IL-1 $\beta$ production in whole blood. The release of TNF $\alpha$ was increased 30 -fold after 16 hours incubation. Intact LL37 also increased LTA-induced TNF $\alpha$ and IL-1 $\beta$ in a time dependent manner. LTA in combination with either LL33 or IG23 demonstrated a synergistic enhanced TNF $\alpha$ and IL-1 $\beta$ secretion on isolated leukocytes but not on purified monocytes. When complexed with IG23 and LL33, the electrophoretic mobility of LTA was altered in a nondenaturating gel electrophoresis. LTA was disaggregated and migrated more rapidly, suggesting an amphiphilic effect of CPs on LTA. In conclusion, LTA synergizes with LL37 and its truncated derivatives and this may lead to proinflammatory cytokine production and cause problems in sepsis therapy.
\end{abstract}

Key Words: Cationic peptides, ELISA, interleukin-1 beta, sepsis, tumor necrosis factor-alpha

\section{Introduction}

The best known pathogen-associated molecular patterns (PAMPs) responsible for an inflammatory response are lipopolysaccharide (LPS, endotoxin), lipoteichoic acid (LTA) and peptidoglycan [1]. LTA is a major cell wall component of Gram-positive bacteria and has an amphiphilic molecular structure, containing a substituted poly(glycerophosphate) backbone attached to a glycolipid. LTA is considered to be the counterpart of LPS derived from Gramnegative bacteria. Once LTA is recognized by tolllike receptor 2, downstream signals trigger the innate immune responses resulting in induction of cytokines such as interleukin-1 $\beta$ (IL-1 $\beta$ ), interleukin-6 (IL-6) and tumor necrosis factor- $\alpha$ (TNF $\alpha)$ [2]. Low concentrations of these cytokines cause beneficial proinflammatory responses and fever, but an excessive response can lead to defect circulation, multi organ failure and death [3]. Antimicrobial peptides (AMPs) play a key role in the protection against PAMPs in almost all forms of multicellular hosts; they are cationic and their microbicidal action is initiated through interactions with the anionic bacterial surface [4]. Furthermore they are surface active agents which may bind to or penetrate through cellular membranes and induce lysis. AMPs exert not only antimicrobial activity but can also interact with free LPS and LTA [5]. There are many studies evaluating interactions between AMPs and LPS however, to date, there have been relatively few studies on AMPs interactions with LTA. However, AMPs neutralize the inflammatory effect of LTA, e.g. Scott et al. showed that CEME and CEME-related peptides inhibited LTA-induced production of TNF $\alpha$ and IL-6 by RAW 264.7 cells and in human whole blood [6] and also that LL37 inhibited TNF $\alpha$ production by LTA in RAW 264.7 cells [7]. Furthermore Kandler et al. [8] showed that LL37 inhibited the

Correspondence: Anna Gustafsson, Malmö University, Faculty of Health and Society, Entrance 49, SE-21428, Malmö, Sweden. Tel: +46 406657416. Fax: +46 40665 8100. E-mail: Anna.Gustafsson@mah.se 
production of IL-6, TNF $\alpha$ and IL-12 induced by LTA on dendritic cells. Nell et al. [9] also demonstrated that LL37 inhibited IL-8 production in whole blood stimulated with LTA.

It has also been shown that LTA synergizes with human proteins to stimulate cytokine secretion from human blood cells, for example LTA is markedly enhanced by hemoglobin $[10,11]$ glycosphingolipids $[12,13]$, or muramyl dipeptide [14].

We have previously shown that cationic peptides (CPs) derived from LL37, SC4 (BPI) and CP107 (CEME) block LPS induced proinflammatory cytokines in whole blood [15]. The CPs were all selected from promising LPS neutralization and binding experiments presented in the literature. Considering that Gram-positive bacteria account for up to $50 \%$ of severe sepsis or septic shock cases [16] we wished to analyse the effect of these CPs on whole blood responses to LTA. The hypothesis was that LTA activation in whole blood should be inhibited by CPs.

\section{Materials and methods}

Butanol-extracted, structurally intact LTA from Staphylococcus aureus (S. aureus) were used (a generous gift of Dr S. von Aulock). LTA were tested for endotoxin contamination in the limulus amoebocyte lysate (LAL) assay (Charles- River/Endosafe, Charleston, USA) and were found to contain less than $0.005 \mathrm{EU} /$ $\mathrm{ml}$. Polymyxin B (PMB) was obtained from Sigma (St. Louis, MO). The CPs were obtained from Innovagen $\mathrm{AB}$ (Lund, Sweden). Purity of $95 \%$ was determined by HPLC. KL12: $\mathrm{NH}_{2}$-KLFKRHLK WKIIC-COOH (derivative from SC4/BPI), KW27: $\mathrm{NH}_{2}$-KWKSFIKKLTSVLKKVVTTAKPLISSC -CCOH (CP207), IG23: $\mathrm{NH}_{2}$-IGKEFKRIVQRIKD FLRNLVPRTC-COOH (LL37, peptide 13-35), LL33: $\quad \mathrm{NH}_{2}$-LLGDFFRKSKEKIGKEFKRIVQR IKDFLRNLVC-COOH (LL37, peptide 1-32), LL37: $\mathrm{NH}_{2}$-LLGDFFRKSKEKIGKEFKRIVQRIKDFL RNLVPRTES-COOH. The truncated peptides were terminated with cystein in the carboxy end in order to specifically immobilize them onto a solid matrix in an equal manner and initially to evaluate the interaction with LPS [15].

\section{Whole blood incubations}

Heparinized blood was obtained from healthy donors. Stock solutions of the different CPs were prepared in LAL water. Each CP $(50 \mu \mathrm{l})$ was mixed with $50 \mu \mathrm{LTA}(100 \mu \mathrm{g} / \mathrm{ml})$ and diluted with $1 \mathrm{ml} 0.9$ $\%$ physiological saline prior to addition of $100 \mu \mathrm{l}$ blood. The mixtures were incubated for $1,3,6,12$, 16 or $24 \mathrm{~h}$ respectively at $37^{\circ} \mathrm{C}$ and $5 \% \mathrm{CO}_{2}$. The final concentration was: LTA $4 \mu \mathrm{g} / \mathrm{ml}$ and CPs 4 or $20 \mu \mathrm{M}$. After incubation, samples were resuspended and spun down $(2 \mathrm{~min}$ at $1000 \mathrm{~g}$ ) and supernatants were analyzed immediately or stored at $-80^{\circ} \mathrm{C}$ until cytokine measurement.

\section{Isolation of human leukocytes}

Mononuclear cell or polymorphonuclear (PMN) cell fractions of human leukocytes were isolated by centrifugation with Polymorphprep (Nycomed Pharma AS, Majorstua, Norway) according to the manufacturer's instructions. After centrifugation, two leukocyte bands (mononuclear cells in the top band and PMNs in the lower one) were obtained which were harvested, washed, and centrifuged (500 $\mathrm{g}, 10 \mathrm{~min}$ ). The autologous plasma on top of the mononuclear cells was also collected. To obtain a mix of leukocytes, both mononuclear cells and PMNs were resuspended in the autologous plasma. For isolation of monocytes, mononuclear cells were plated in 96-well tissue culture plates at $10^{6} / \mathrm{ml}(100 \mu \mathrm{l} /$ well $)$ and after $2 \mathrm{~h}$ at $37^{\circ} \mathrm{C}, 5 \% \mathrm{CO}_{2}$ the lymphocytes were washed away with $0.9 \%$ saline and to the adherent monocytes $0.9 \%$ saline containing $5 \%$ autologous plasma was added. PMNs were plated in 96-well tissue culture plates at $2.5 \times 10^{6} / \mathrm{ml}(100 \mu \mathrm{l} /$ well $)$ suspended in $0.9 \%$ saline containing $5 \%$ autologous plasma.

\section{Stimulation of human leukocytes}

Stock solution of IG23 were prepared in LAL water and mixed with LTA and hemoglobin $(\mathrm{Hb})$. Each sample of $100 \mu \mathrm{l}$ was diluted with $1 \mathrm{ml} 0.9 \%$ saline and incubated with $100 \mu \mathrm{l}$ isolated leukocytes at 1 , $3,6,12$, or $24 \mathrm{~h}$ respectively at $37^{\circ} \mathrm{C}$ and $5 \% \mathrm{CO}_{2}$ in a $1.5 \mathrm{ml}$ polypropylene reaction vial. The final concentration was: LTA $4 \mu \mathrm{g} / \mathrm{ml}$, IG23 $20 \mu \mathrm{M}$ and $\mathrm{Hb} 50 \mu \mathrm{g} / \mathrm{ml}$. Release of TNF $\alpha$ was quantified after the indicated hours.

\section{Stimulation of human monocytes and PMNs}

Isolated monocytes $\left(10^{6} / \mathrm{ml}\right)$ or PMNs $\left(2.5 \times 10^{6} /\right.$ $\mathrm{ml}$ ) in $0.9 \%$ saline containing $5 \%$ autologous plasma were treated with LTA $(4 \mu \mathrm{g} / \mathrm{ml})$ and IG23, LL33 or PMB $(20 \mu \mathrm{M})$ for 3 and $9 \mathrm{~h}$ respectively. Aliquots of the culture medium were assayed immediately for IL- $1 \beta$ and TNF $\alpha$ release.

\section{Cytokine ELISA}

IL-1 $\beta$, IL-6 andTNF $\alpha$ were quantified using ELISA Set (BD OptEIA by BD Opt EIA Biosciences, San Diego USA) according to the manufacturer's instructions. Assays were carried out in flat-bottom 96-well immunoplates (MaxiSorp, nunc, Wiesbaden Germany).

\section{Cell viability with Alamar Blue}

The impact on cell viability of the CPs and LTA was evaluated using the Alamar Blue assay [17]. Experiments were carried out in 96-well black plates with 
a clear bottom (Costar, Corning Inc., Corning, NY, USA) to minimize fluorescence interference between wells. The CPs $(20 \mu \mathrm{M})$ with or without LTA $(4 \mu \mathrm{g} /$ $\mathrm{ml})$ were incubated with either whole blood (1:10 in $0.9 \%$ saline) or leukocytes ( $1: 10$ in $0.9 \%$ saline, isolated from human whole blood, see isolation of human leukocytes), or monocytes (isolated from human blood, $10^{6} / \mathrm{ml}$ in $0.9 \%$ saline with $5 \%$ autologous plasma) or PMNs (isolated from human blood, $2.5 \times 10^{6} / \mathrm{ml}$ in $0.9 \%$ saline with $5 \%$ autologous plasma) $20 \mathrm{~h}$ at $37^{\circ} \mathrm{C}$ and $5 \% \mathrm{CO}_{2}$. The Alamar Blue solution (1/10) (Biotium, Inc, CA, USA) was added to each well and cells incubated for $4 \mathrm{~h}$. The fluorescence intensity was measured on a Spectra Max Gemini XS microplate spectrofluorometer (Molecular Device, Sunnyvale, CA; USA) with an excitation wavelength of $545 \mathrm{~nm}$ and an emission wavelength of $590 \mathrm{~nm}$. Whole blood samples were centrifuged (300 $\mathrm{g}$ for $2 \mathrm{~min}$ ) before measurement. The fluorescence values were normalized by the controls (untreated cells) and expressed as percent viability.

\section{Hemolytic activity of CPs}

Human erythrocytes were obtained from freshly collected whole blood, centrifuged at $800 \mathrm{~g}$ for $10 \mathrm{~min}$, and washed with $20 \mathrm{mM}$ Hepes buffer with $150 \mathrm{mM} \mathrm{NaCl}$ $\mathrm{pH}$ 7.4. The assay was performed in Hepes buffer with $150 \mathrm{mM} \mathrm{NaCl}$ by incubating $2.5 \%$ (vol/vol) erythrocyte suspensions with various amounts of CPs $(0-200 \mu \mathrm{M})$ for $30 \mathrm{~min}$ at $37^{\circ} \mathrm{C}$. After centrifugation at $800 \mathrm{~g}$ for $10 \mathrm{~min}$, the supernatant was carefully removed, and the release of hemoglobin measured at $577 \mathrm{~nm}$. The percentage of hemolysis was determined as $\left(\mathrm{A}_{\text {peptide }}-\mathrm{A}_{\text {blank }}\right) /\left(\mathrm{A}_{\text {tot }}-\mathrm{A}_{\text {blank }}\right) \times 100$, where $\mathrm{A}_{\text {blank }}$ and $A_{\text {tot }}$ correspond respectively to the hemolysis in the absence of the CPs and to $100 \%$ hemolysis as obtained by addition of $2 \%$ Triton X-100.

\section{Nondenaturating PAGE of LTA/CP mixtures and staining procedure}

LTA $(10 \mu \mathrm{g})$ were incubated in the absence or presence of $1 \mu \mathrm{g}$ or $10 \mu \mathrm{g} \mathrm{IG} 23$, LL33 or PMB, respectively, for $30 \mathrm{~min}$ at $37^{\circ} \mathrm{C}$. As controls $10 \mu \mathrm{g} \mathrm{IG} 23$, LL33 or PMB without LTA was incubated. Samples were resolved in tris-glycine buffer (25 mMTris, $\mathrm{pH} 8.3,192$ $\mathrm{mM}$ glycine) on a $12 \%$ native polyacrylamide gel at 200V. Following electrophoresis, gels were stained using Bio-Rad Silver Stain kit (Bio-Rad, Munich, Germany) according to the manufacturer's instructions.

\section{Statistical analysis}

All experiments were performed in duplicate a minimum of three times. Values are presented as means \pm standard deviation (SD). In case of two groups, data was analysed with paired t-test. Differences were considered significant when $p<0.05\left({ }^{*} 0.01<p<\right.$ $\left.0.05 ;{ }^{* *} 0.001<p<0.01 ;{ }^{* * *} p<0.001\right)$.

\section{Results}

Cytokine release after whole blood incubations

Experiments with LTA incubations in whole blood showed that CPs enhanced LTA-induced IL- $1 \beta$ production (significant for KL12, IG23 and LL33) and more over IG23 and LL33 also significantly enhanced LTA induced production of both TNF $\alpha$ and IL- 6 as depicted in Figure 1. Pure CPs $(20 \mu \mathrm{M})$ did not induce any detectable cytokine production. KW27 had no effect on LTA-induced cytokine production in whole blood. PMB significantly enhanced IL- $1 \beta$ production but had no effect on IL-6 or TNF $\alpha$. Since IG23 and LL33 had the strongest effect on LTA-induced cytokine secretion a time study with these CPs was made, in this experiment intact LL37 was included. As shown in Figure 2, IG23, LL33 and LL37 all potentiated LTA-induced IL- $1 \beta$ secretion and $\mathrm{TNF} \alpha$ secretion in a time-dependent manner. Regarding $\mathrm{TNF} \alpha$ secretion, it looked like the CPs induced a biphasic pattern as compared to LTA only. There was a very big biological variation in $\mathrm{TNF} \alpha$ induction among the blood donors tested. This variation can be seen by comparing Figure 1 and 2. In Figure $1(n=9) \mathrm{TNF} \alpha$ production was increased 30 -fold after $16 \mathrm{~h}$ while Figure $2 \mathrm{~B}(n=5)$ shows that $\mathrm{TNF} \alpha$ production was increased 3-fold after $12 \mathrm{~h}$. A lower concentration of the CPs was also tested; LL33 showed the same enhancement of LTA-induced cytokine production at $4 \mu \mathrm{M}$ while IG23 of $4 \mu \mathrm{M}$ showed no difference compared to LTA-treated cells as depicted in Figure 2C. To ensure that heparin did

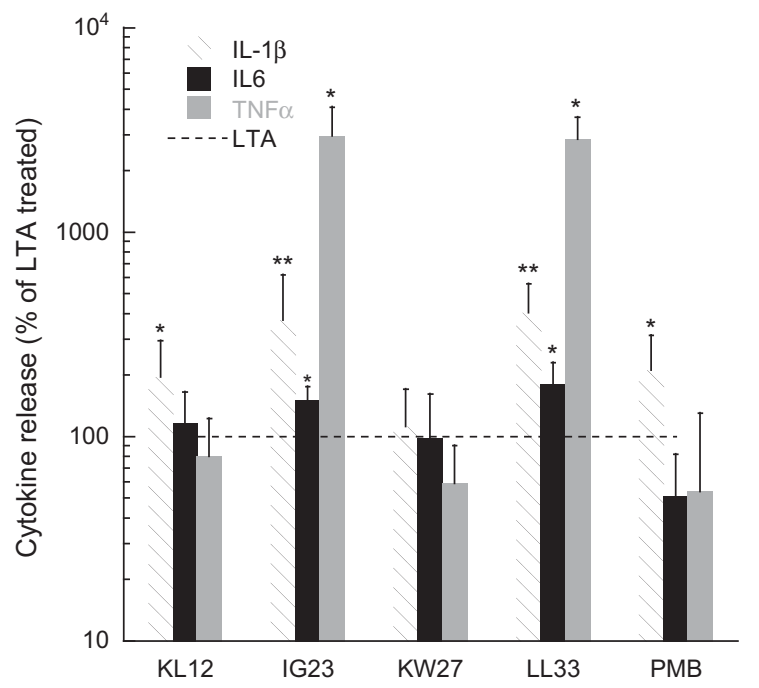

Figure 1. Cytokine release from leukocytes in stimulated human whole blood. Production of proinflammatory cytokines by cells in whole blood stimulated with CPs $(20 \mu \mathrm{M})$ and LTA $(4 \mu \mathrm{g} / \mathrm{ml})$ for $16 \mathrm{~h}$. Supernatants were analysed with ELISA to determine the concentrations of IL-1 $\beta$ (hatched bar), IL-6 (black bar), and TNF $\alpha$ (grey bar). Pure CPs $(20 \mu \mathrm{M})$ without LTA showed no detectable cytokine production (not shown). Results are presented as cytokine release ( $\%$ of LTA treated), means \pm SD of nine independent experiments. (*) indicates a significant difference compared to LTAinduced cytokine production. Note the log scale on the $\mathrm{x}$-axis. 

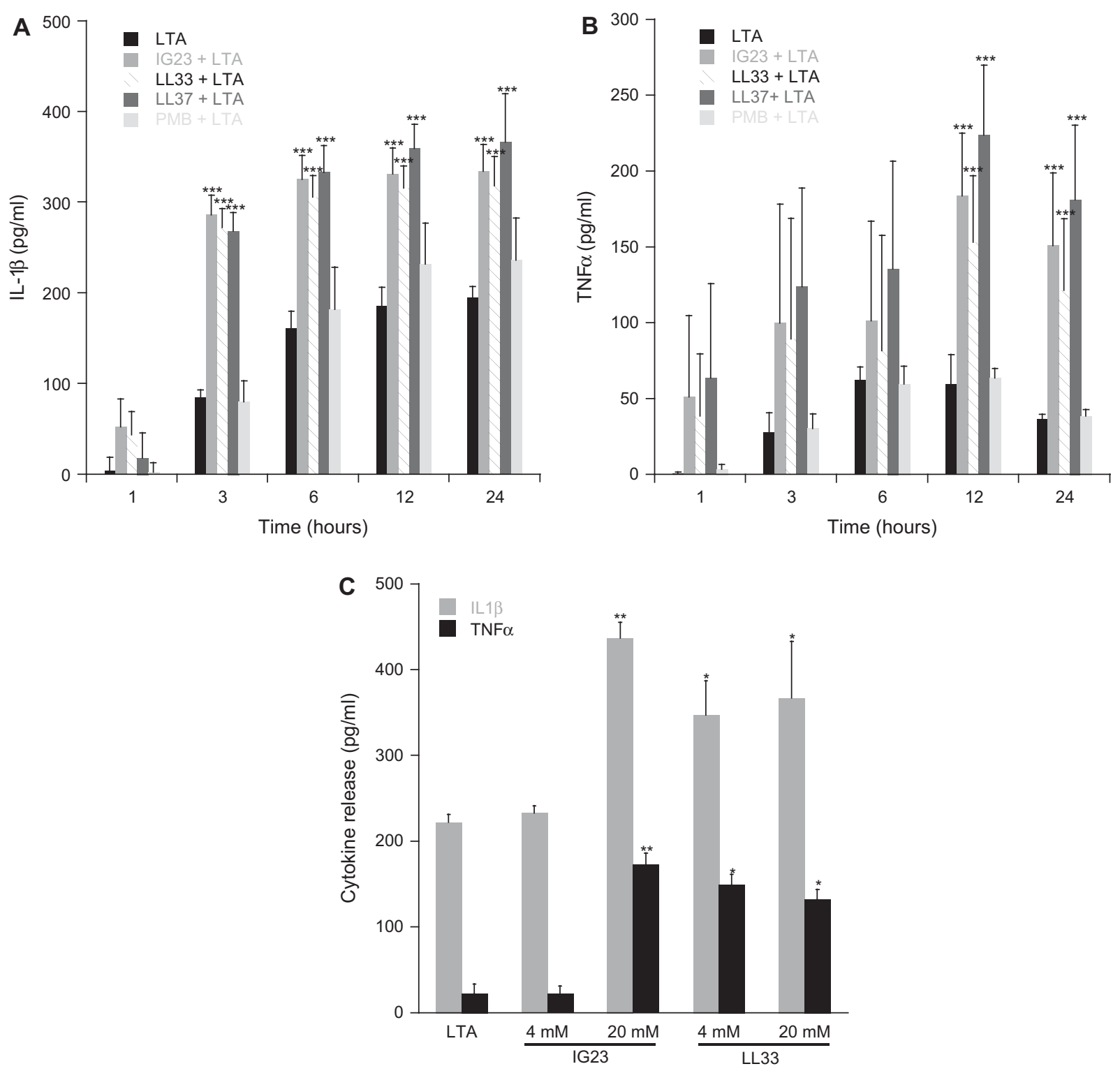

Figure 2. IG23, LL33 and LL37 potentiation of LTA-induced cytokine release in whole blood. Production of IL-1 $\beta$ (A) and TNF $\alpha$ (B) by leukocytes in whole blood stimulated with IG23, LL33, LL37 or PMB $(20 \mu \mathrm{M})$ and LTA $4 \mu \mathrm{g} / \mathrm{ml}$ for 1,3, 6, 12 and 24 h. Pure IG23, LL33, LL37 or PMB $(20 \mu \mathrm{M})$ without LTA showed no detectable cytokine production (not shown). Figure C shows production of IL-1 $\beta$ and TNF $\alpha$ after $24 \mathrm{~h}$ by leukocytes in whole blood stimulated with IG23 or LL33 of $4 \mu \mathrm{M}$ and $20 \mu \mathrm{M}$ and LTA $4 \mu \mathrm{g} / \mathrm{ml}$. Results are presented as cytokine concentrations $(\mathrm{pg} / \mathrm{ml})$, means $\pm \mathrm{SD}$ of five independent experiments. Values marked $(*)$ indicates a significant difference compared to LTA-induced cytokine release.

not interfere with the signalling, EDTA blood and citrate were also tested. Those experiments showed the same pattern as heparinized blood although not resulting in such high cytokine levels (result not shown).

\section{Stimulation of PMNs and monocytes}

In order to complement the whole blood assay, we looked at purified components. No cytokine release was observed upon stimulation of PMNs with either LTA or in combination with the CPs, IG23 or LL33. The experiments on human monocytes showed that LL33 significantly inhibited LTA-induced IL- $1 \beta$ and $\mathrm{TNF} \alpha$ secretion after 3 and $9 \mathrm{~h}$ as depicted in Figure 3. IG23 significantly inhibited TNF $\alpha$ secretion but not IL-1 $\beta$ secretion. PMB had no effect on LTA-induced
$\mathrm{TNF} \alpha$ production but a significantly inhibited LTAinduced IL-1 $\beta$ secretion was observed.

\section{Hemolysis}

Since $\mathrm{Hb}$ has been shown to stimulate LTA the hemolytic effects of the CPs were analysed. KW27, LL33 and IG23 induced a concentration dependent hemolysis (Figure 4). KL12 and PMB were considered to be non hemolytic in the concentrations tested. In order to determine whether hemolysis played a role in CPs potentiating of LTA-induced cytokine secretion leukocytes (monocytes, lymphocytes, granulocytes and thrombocytes) without red blood cells were incubated with IG23, LTA and $\mathrm{Hb}$. As shown in Figure 5, Hb itself enhanced LTA-induced TNF $\alpha$ secretion as previ- 


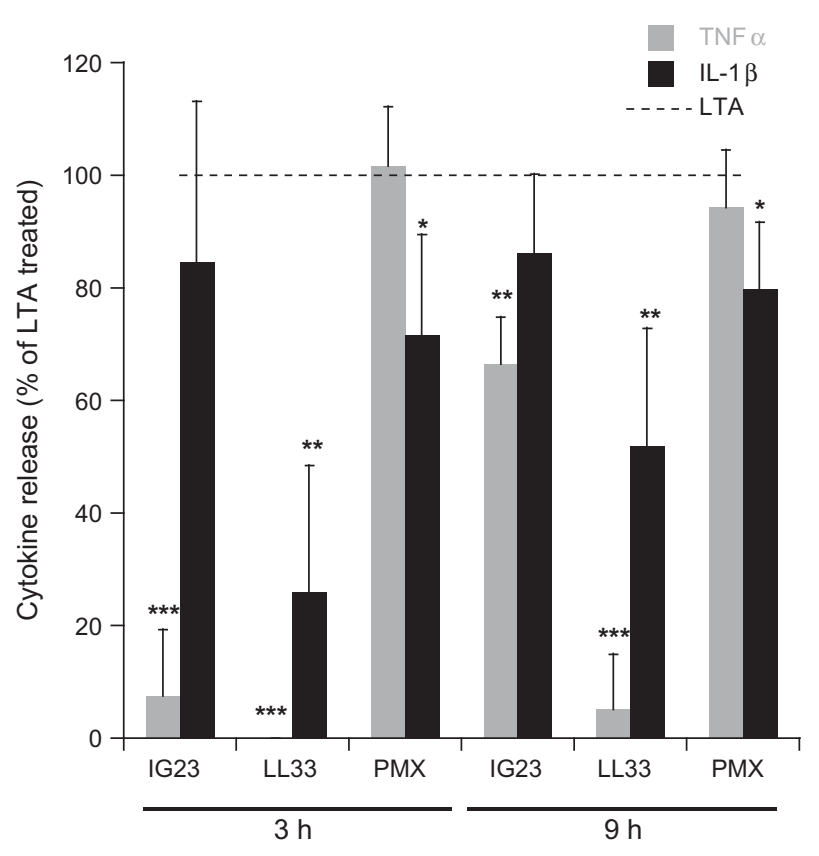

Figure 3. Cytokine release from human monocytes. Effect of IG23, LL33 and PMB on LTA-induced monocyte activation. Isolated monocytes were challenged with LTA $(4 \mu \mathrm{g} / \mathrm{ml})$ and peptides LL33, IG23 and PMB $(20 \mu \mathrm{M})$. Release of TNF $\alpha$ and IL-1 $\beta$ was quantified after 3 and $9 \mathrm{~h}$ of incubation, and quantity is expressed as a percentage of LTA-induced cytokine release. Means \pm SD of six experiments are shown. Values marked (*) differ significantly from cytokine release induced by LTA in the absence of CPs.

ously published $[10,11]$. Interestingly, also IG23 itself enhanced LTA-induced TNF $\alpha$ secretion. IG23 and $\mathrm{Hb}$ together gave an even stronger enhancement of LTA-induced TNF $\alpha$ secretion in human leukocytes.

\section{Cell viability}

Peptide concentrations of $20 \mu \mathrm{M}$ did not affect the viability of the monocytes, PMNs, leukocytes (1:10 in saline), or in whole blood (1:10 in saline) after $24 \mathrm{~h}$ incubation with or without LTA $(4 \mu \mathrm{g} / \mathrm{ml})$. Considering that KW27 and LL33 are hemolytic in the concentration tested (see Figure 4), hemoglobin interfered with the fluorescence measurements in the Alamar Blue assay in whole blood and gave a false low fluorescence. Leukocytes challenged with LL33 or KW27 $(20 \mu \mathrm{M})$ together with $\mathrm{Hb}(1 \mathrm{mg} / \mathrm{ml})$ showed no reduction of fluorescence compared to leukocytes treated with only $\mathrm{Hb}(1 \mathrm{mg} / \mathrm{ml})$.

\section{Nondenaturating PAGE of LTA/CP mixtures}

To determine whether the synergistic effect of the LTA-CPs mixtures could be due to physical interactions between the two molecules a non-denaturating gel electrophoresis was performed followed by silver staining. Although LTA migrates on a SDS-PAGE gel at $\sim 8-10 \mathrm{kDa}$, it migrates much slower and in a diffuse manner on a nondenaturating gel (see Figure 6). This migration pattern may be explained by the ability of LTA to form micelles in aqueous

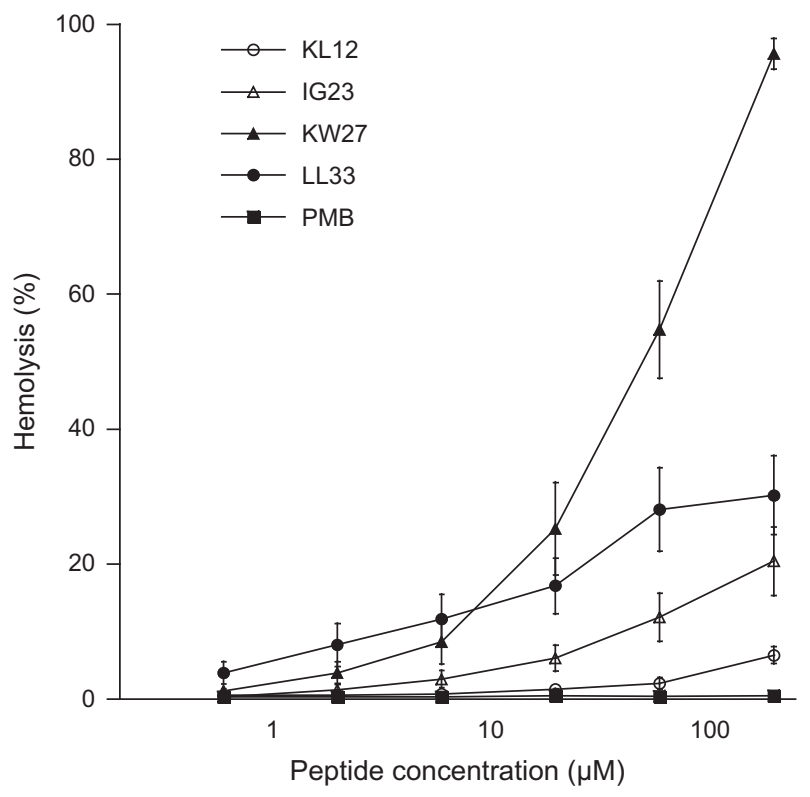

Figure 4. Hemolytic activity. Concentration-response curve of the hemolytic activity of the peptides towards human erythrocytes. Results are presented as means \pm SD of three independent experiments. Note the log scale on the $\mathrm{x}$-axis.

solution [18]. Figure 6 shows that when incubated with LL33 or IG23 at weight ratio 1:1, LTA disaggregates and migrates faster and more diffusely. PMB had no effect on LTA migration.

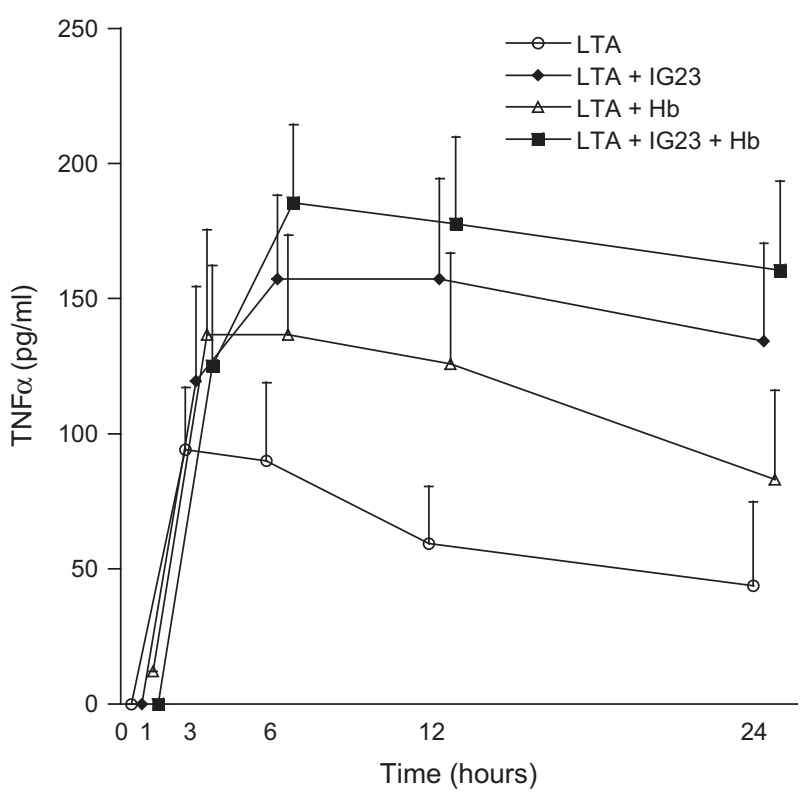

Figure 5. Effect of Hb and IG23 on LTA-induced leukocyte activation. Isolated leukocytes (monocytes, lymphocytes, granulocytes and thrombocytes) were challenged with LTA $(4 \mu \mathrm{g} / \mathrm{ml})$, IG23 $(20 \mu \mathrm{M})$ and $\mathrm{Hb}(50 \mu \mathrm{g} / \mathrm{ml})$. Release of $\mathrm{TNF} \alpha$ was quantified after 1, 3, 6, 12 and $24 \mathrm{~h}$ of incubation. Results are presented as $\mathrm{TNF} \alpha$ concentration $(\mathrm{pg} / \mathrm{ml})$, means $\pm \mathrm{SD}$ of three independent experiments. The differences are significant between LTA/Hb-, LTA/ IG23- and LTA/Hb/IG23-induced cytokine production compared to LTA-induced production. Pure IG23 and IG23/Hb without LTA showed no detectable cytokine production (not shown). Note that points for each sampling hour are a little apart to discern SD bars. 


\section{Discussion}

The roles of CPs as therapeutic agents are of great importance at the present moment as the research on new antibiotic drugs have limited interest within the pharmaceutical industry. The use of CPs for the treatment of Gram-positive sepsis would be beneficial as previously demonstrated for Gram-negative sepsis. The general hypothesis is that CPs neutralize the inflammatory effects of LTA. This study showed the opposite since costimulation with some CPs and LTA from $S$. aureus, the most prevalent Gram-positive pathogen, potentiate the induced production of the pro-inflammatory cytokines IL- $1 \beta$, IL- 6 and $\mathrm{TNF} \alpha$ in whole blood. In other words, CPs may contribute to the inflammation caused by LTA rather than inhibit it. In particular, IG23 and LL33, truncated derivatives from the cathelicidin hCAP18, induced high levels of TNF $\alpha$ in whole blood and leukocytes. hCAP18 is present in human PMNs, and is expressed throughout epithelia in many organs and can be cleaved extracellular to generate the AMP LL37 [19]. It has been demonstrated that some CPs inhibit cytokine production by monocytes or in whole blood stimulated with commercial available LTA from $S$. aureus. For example, Scott et al. [6] showed that CP207 which differs from KW27 only at the C-terminal end, where KW27 has an additional cystein residue, inhibited LTA-stimulated (S. aureus, $B$. subtilius and $S$. pyrogenes from Sigma) production of TNF $\alpha$ and IL- 6 induction by RAW 264.7 cells. In the present study KW27 had no effect on LTA-induced cytokine production in whole blood, the effect on isolated monocytes was not tested. KL12 has previously been shown to have good activity against gram-positive bacteria [20] and in the present study it potentiated LTA-induced IL-1 $\beta$ production. Kandler et al. [8] showed that LL37 inhibited the production of IL-6, TNF $\alpha$ and IL-12 induced by commercial LTA on dendritic cells. In the present study IG23 and LL33 inhibited LTA-induced TNF $\alpha$ production on monocytes but not in whole blood or the leukocyte mix. These results indicate that a whole blood system, i.e. interactions

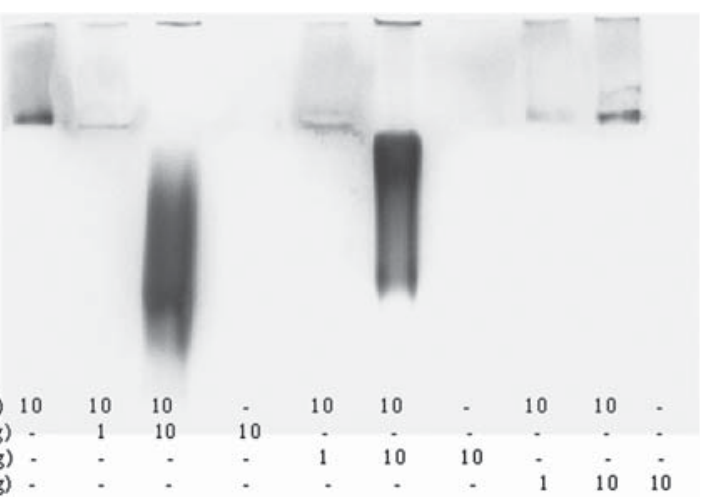

Figure 6. Migration of LTA/CP mixtures on native polyacrylamide gels. LTA were incubated in the absence or presence of LL33, IG23 or PMB at two different weight ratios. Following electrophoresis, gels were stained with silver staining. between the leukocytes, rather than isolated monocytes is essential for the enhanced LTA-induced cytokine secretion by LL37.

It has been demonstrated that commercial preparations of LTA contains significant amounts of endotoxin $[21,22]$, which contributes to the observed biological activities such as induction of inflammatory mediators in various types of cells. Chromatographic purification of commercially $S$. aureus LTA eliminates its immunostimulatory potential [22-24]. Morath et al. [23] demonstrated that commercial LTA contained considerable contamination by non-LTA, non-LPS immunostimulatory contamination in HIC fractions not typical for either LTA or LPS. There are also doubts about the quality of the commercial preparations of LTA. Morath et al. [25] revealed that alanine substituents are lost during phenol extraction. In the present study LTA were purified using butanol extraction to preserve D-alanine constituents, which are important to maintain the LTA proinflammatory activity [25].

Deininger et al. [26] showed that adhesion of LTA to a polystyrene surface drastically increased its immunostimulatory potency in human whole blood in comparison to soluble LTA. The release of the proinflammatory cytokines IL-1 $\beta, \mathrm{TNF} \alpha$ and IL- 6 and the chemokines IL-8 and G-CSF was increased 2- to 10-fold, but IL-10 release was unaltered. These findings indicated that LTA is only recognized by immune cells when it is presented on a surface. They also described that both LTA adhering to a surface and LTA covalently coupled on to a surface are able to induce cytokine release [26]. Draing et al. [27] investigated whether LTA monomers in solution can activate monocytes. They incubated monocytes in different vials, which did not allow LTA binding, as well as various beads binding LTA. Their results showed that when no binding of LTA to surfaces was possible, blood monocytes were not able to react to LTA.

It has previously been shown that stimulation of human monocytes by LTA is markedly enhanced by $\mathrm{Hb}$ $[10,11]$. Their hypothesis is that LTA forms a complex with $\mathrm{Hb}$ in a way that facilitates the presentation of LTA to the macrophage Toll-like receptors. In the present study, hemolysis is likely to contribute to the effect in whole blood considering the hemolytic effect of LL33 and IG23. However, Figure 5 shows that stimulation of leukocytes by LTA is enhanced by IG23 both with and without $\mathrm{Hb}$. Moreover it is well known that the hemolytic effect of cationic peptides is drastically reduced in the presence of plasma $[28,29]$. The increased reactivity of LTA, when complexed with IG23 and LL33 and the altered electrophoretc mobility of LTA (Figure 6) may be explained by an amphiphilic effect of CPs on LTA, making LTA more attractive for activation of human leukocytes. The interaction of LTA with $\mathrm{Hb}$ and glycosphingolipids has also been shown to change the migration of LTA in a nondenaturation gel $[10,13]$.

This study has demonstrated that CPs, which binds LPS with high affinity [15], can interact synergistically 
with LTA and potentiate the induced cytokine production in whole blood, in a time- and concentrationdependent manner. The mechanism behind this must be evaluated further but nevertheless, some CPs can perhaps cause problems in treatment of Gram-positive sepsis. Although LTA is integrated in the cell wall of Gram-positive bacteria it can be released when bacteria are killed by either the host immune system or antibiotic treatment [16]. The interactions between free LTA and some CPs may activate immune cells and lead to induction of cytokine production rather than inhibition. The derivatives in this study were terminated with cystein. It is well known that cystein residues may lead to a formation of disulfide bonds that in this case could alter the interaction affinity for LTA. However, in the present study regarding the potentiation of proinflammatory cytokine release similar effects have been observed for LL37 without the presence of cystein. It would be of great interest to evaluate neutralization of LTA using these CPs when immobilized onto solid phases.

\section{Acknowledgements}

We thank Fatima Barakat for excellent technical assistance.

Declaration of interest: The authors declare no competing financial interests.

\section{References}

[1] Daneshian M, Wendel A, Hartung T, von Aulock S. High sensitivity pyrogen testing in water and dialysis solutions. J Immunol Methods 2008;336:64-70.

[2] Kinsner A, Boveri M, Hareng L, Brown GC, Coecke S, Hartung T, Bal-Price A. Highly purified lipoteichoic acid induced pro-inflammatory signalling in primary culture of rat microglia through Toll-like receptor 2: selective potentiation of nitric oxide production by muramyl dipeptide. J Neurochem 2006;99:596-607.

[3] Wanecek M, Weitzberg E, Rudehill A, Oldner A. The endothelin system in septic and endotoxin shock. Eur J Pharmacol 2000;407:1-15.

[4] Gura T. Innate immunity. Ancient system gets new respect. Science 2001;291:2068-71.

- [5] Hancock RE. Cationic peptides: effectors in innate immunity and novel antimicrobials. Lancet Infect Dis 2001;1:156-64.

[6] Scott MG, Gold MR, Hancock RE. Interaction of cationic peptides with lipoteichoic acid and gram-positive bacteria. Infect Immun 1999;67:6445-53.

[7] Scott MG, Davidson DJ, Gold MR, Bowdish D, Hancock RE. The human antimicrobial peptide LL-37 is a multifunctional modulator of innate immune responses. J Immunol 2002;169:3883-91.

- [8] Kandler K, Shaykhiev R, Kleemann P, Klescz F, Lohoff M, Vogelmeier C, Bals R. The anti-microbial peptide LL-37 inhibits the activation of dendritic cells by TLR ligands. Int Immunol 2006;18:1729-36.

[9] Nell MJ, Tjabringa GS, Wafelman AR, Verrijk R, Hiemstra PS, Drijfhout JW, Grote JJ. Development of novel LL-37 derived antimicrobial peptides with LPS and LTA neutralizing and antimicrobial activities for therapeutic application. Peptides 2006;27:649-60.

[10] Hasty DL, Meron-Sudai S, Cox KH, Nagorna T, RuizBustos E, Losi E. Monocyte and macrophage activation by lipoteichoic acid is independent of alanine and is potentiated by hemoglobin. J Immunol 2006;176:5567-76.

[11] Cox KH, Ofek I, Hasty DL. Enhancement of macrophage stimulation by lipoteichoic acid and the costimulant hemoglobin is dependent on Toll-like receptors 2 and 4 . Infect Immun 2007;75:2638-41.

[12] Traub S, von Aulock S, Hartung T, Hermann C. MDP and other muropeptides - direct and synergistic effects on the immune system. J Endotoxin Res 2006;12:69-85.

[13] Meron-Sudai S, Matityahou A, KeisariY, Cox KH, Hasty DL, Ofek I. Lipoteichoic acid synergizes with glycosphingolipids to potently stimulate secretion of interleukin- 6 from human blood cells. Clin Vaccine Immunol 2008;15:1309-15.

[14] Kim HJ, Yang JS, Woo SS, Kim SK, Yun CH, Kim KK, Han SH. Lipoteichoic acid and muramyl dipeptide synergistically induce maturation of human dendritic cells and concurrent expression of proinflammatory cytokines. J Leukoc Biol 2007;81:983-9.

[15] Gustafsson A, Olin AI, Ljunggren L. LPS interactions with immobilized and soluble antimicrobial peptides. Scand J Clin Invest 2010;70:194-200.

[16] Ginsburg I. Role of lipoteichoic acid in infection and inflammation. Lancet Infect Dis 2002;2:171-9.

[17] Nakayama GR, Caton MC, Nova MP, Parandoosh Z. Assessment of the Alamar Blue assay for cellular growth and viability in vitro. J Immunol Methods 1997;204:205-8.

[18] Fischer W, Markwitz S, Labischinski H. Small-angle X-ray scattering analysis of pneumococcal lipoteichoic acid phase structure. Eur J Biochem 1997;244:913-7.

[19] Sorensen OE, Follin P, Johnsen AH, Calafat J, Tjabringa GS, Hiemstra PS, Borregaard N. Human cathelicidin, hCAP-18, is processed to the antimicrobial peptide LL- 37 by extracellular cleavage with proteinase 3. Blood 2001;97:3951-9.

[20] Mayo KH, Haseman J, Young HC, Mayo JW. Structurefunction relationships in novel peptide dodecamerswith broad-spectrum bactericidal and endotoxin-neutralizing activities. Biochem J 2000;349 Pt 3:717-28.

[21] Sugiyama A, Arakaki R, Ohnishi T, Arakaki N, Daikuhara Y, Takada H. Lipoteichoic acid and interleukin 1 stimulate synergistically production of hepatocyte growth factor (scatter factor) in human gingival fibroblasts in culture. Infect Immun 1996;64:1426-31.

-[22] Gao JJ, Xue Q, Zuvanich EG, Haghi KR, Morrison DC. Commercial preparations of lipoteichoic acid contain endotoxin that contributes to activation of mouse macrophages in vitro. Infect Immun 2001;69:751-7.

[23] Morath S, Geyer A, Spreitzer I, Hermann C, Hartung T. Structural decomposition and heterogeneity of commercial lipoteichoic acid preparations. Infect Immun 2002;70: 938-44.

[24] Kusunoki T, Hailman E, Juan TS, Lichenstein HS, Wright SD. Molecules from Staphylococcus aureus that bind CD14 and stimulate innate immune responses. J Exp Med 1995; 182:1673-82.

[25] Morath S, Geyer A, Hartung T. Structure-function relationship of cytokine induction by lipoteichoic acid from Staphylococcus aureus. J Exp Med 2001;193:393-7.

[26] Deininger S, Traub S, Aichele D, Rupp T, Baris T, Moller HM. Presentation of lipoteichoic acid potentiates its inflammatory activity. Immunobiology 2008;213:519-29.

[27] Draing C, Sigel S, Deininger S, Traub S, Munke R, Mayer C. Cytokine induction by Gram-positive bacteria. Immunobiology 2008;213:285-96.

[28] Stromstedt AA, Pasupuleti M, Schmidtchen A, Malmsten $M$. Evaluation of strategies for improving proteolytic resistance of antimicrobial peptides by using variants of EFK17, an internal segment of LL-37. Antimicrob Agents Chemother 2009;53:593-602.

[29] Wang Y, Agerberth B, Lothgren A, Almstedt A, Johansson J. Apolipoprotein A-I binds and inhibits the human antibacterial/ cytotoxic peptide LL-37. J Biol Chem 1998;273:33115-8. 